\title{
Monolayer Passivation of Ge(100) Surface via Nitridation and Oxidation
}

\author{
Joon Sung Lee ${ }^{\mathrm{a}, \mathrm{b}}$, Sarah R. Bishop ${ }^{\mathrm{a}}$, Tobin Kaufman-Osborn ${ }^{\mathrm{a}, \mathrm{b}}$, Evgueni Chagarov ${ }^{\mathrm{a}}$, and \\ Andrew C. Kummel ${ }^{\mathrm{a}}$ \\ a Department of Chemistry and Biochemistry, University of California at San Diego, \\ La Jolla, California 92093, USA \\ ${ }^{\mathrm{b}}$ Materials Science and Engineering Program, University of California at San Diego, \\ La Jolla, California 92093, USA
}

The monolayer passivation of $\mathrm{Ge}(100)$ surface via formation of Ge-N and Ge-O surface species was studied using scanning tunneling microscopy (STM) and density functional theory (DFT). Direct nitridation using an electron cyclotron resonance (ECR) plasma source formed an ordered Ge-N structure on a $\mathrm{Ge}(100)$ surface at $500^{\circ} \mathrm{C}$. DFT calculations found the hydrogen passivation on this Ge-N ordered structure could reduce the bandgap states by decreasing the dangling bonds and the bond strain. Oxidation of $\mathrm{Ge}(100)$ using $\mathrm{H}_{2} \mathrm{O}$ produced an $-\mathrm{OH}$ and $-\mathrm{H}$ terminated surface with very few $\mathrm{Ge}$ ad-atoms, while e-beam evaporation of $\mathrm{GeO}_{2}$ formed semi-ordered $\mathrm{Ge}-\mathrm{O}$ structures and $\mathrm{Ge}$ ad-species at room temperature. Annealing above $300^{\circ} \mathrm{C}$ formed suboxide rows on both $\mathrm{H}_{2} \mathrm{O}$ and $\mathrm{GeO}_{2}$ dosed surfaces, and the scanning tunneling spectroscopy (STS) showed that the Fermi level was pinned near the valence band edge on the $n$-type Ge surfaces covered by suboxides.

\section{Introduction}

Germanium is considered a promising channel material for the next generation MOSFET devices due to its favorable electronic properties (e.g. high electron and hole mobilities) compared to $\mathrm{Si}$. However, high defect densities at the interface between $\mathrm{Ge}$ and high-k dielectric layers have been a challenging issue in fabricating scaled devices. Among several different methods to passivate the Ge surface (1-3), nitridation (4-6) and oxidation (7-11) have shown the most promising results.

Nitridation of Ge has been studied using thermal $\left(\mathrm{NH}_{3}\right)$ (4) or a plasma nitridation (atomic N) (5-6) sources to form Ge oxynitride $\left(\mathrm{GeO}_{\mathrm{x}} \mathrm{N}_{\mathrm{y}}\right)$ or Ge nitride $\left(\mathrm{Ge}_{3} \mathrm{~N}_{4}\right)$. These layers have better thermal stability than Ge oxide (12-13); therefore, they suppress the $\mathrm{GeO}$ outdiffusion from $\mathrm{Ge}$ surfaces to the high-k dielectric layer during processing at elevated temperatures, resulting in a low interface defect density (5). A stoichiometric $\mathrm{GeO}_{2}$ layer produced by ozone (9) or high pressure oxidation (11) is also effective in passivating Ge surfaces by eliminating interface defects due to suboxides and dangling bonds. However, for a practical MOSFET device with a high-k dielectric layer, these passivation layers should be scaled down to one or two monolayers.

In this study, the geometric and electronic properties of a $\mathrm{Ge}(100)$ surface at an initial stage of nitridation or oxidation were studied; the low coverage reactions are crucial to 
understanding the physical or chemical origin of defect formation that can occur in the ultrathin passivation layer. Submonolayer nitride structures were formed on a $\mathrm{Ge}(100)$ surface by plasma nitridation and were probed using scanning tunneling microscopy and spectroscopy (STM/STS). Density Functional Theory (DFT) calculations were performed on a model structure to support the experimental data. Oxidation of $\operatorname{Ge}(100)$ was performed using $\mathrm{H}_{2} \mathrm{O}$ and e-beam evaporation of $\mathrm{GeO}_{2}$, and the results were compared with the $\mathrm{O}_{2}$ dosed $\mathrm{Ge}(100)$ surface (14).

\section{Experimental Details}

A Ge sample was cut from the $n$-type $\mathrm{Ge}(100)$ wafer (Sb-doped, 0.005-0.020 Ohm$\mathrm{cm}$ ), and immediately transferred into the ultrahigh vacuum (UHV) chamber at a base pressure of $2 \times 10^{-10}$ Torr. The native oxide of Ge(100) surface was removed using $0.9 \mathrm{kV}$ $\mathrm{Ar}^{+}$ion sputtering at $500^{\circ} \mathrm{C}$ for $30 \mathrm{~min}$, followed by thermal annealing at $800^{\circ} \mathrm{C}$ for 20 min. Direct nitridation of $\mathrm{Ge}(100)$ surface was performed using an electron cyclotron resonance (ECR) plasma with pure $\mathrm{N}_{2}$ gas. To avoid oxygen contamination due to trace $\mathrm{O}_{2}$ or $\mathrm{H}_{2} \mathrm{O}$, the substrate temperature was maintained at $500^{\circ} \mathrm{C}$ during the plasma nitridation. Oxidation of the Ge surface was carried out using two different oxidants $\mathrm{H}_{2} \mathrm{O}$ and $\mathrm{GeO}_{2} \cdot \mathrm{H}_{2} \mathrm{O}$ (HPLC grade) was carefully degassed and dosed onto a $\mathrm{Ge}(100)$ surface through a differentially-pumped dosing system. E-beam evaporation was used for the deposition of $\mathrm{GeO}_{2}(99.999 \%$, metals basis). The atomic and electronic structures of the sample surface were observed using scanning tunneling microscopy and spectroscopy (STM/STS), while Auger electron spectroscopy (AES) was used to analyze the chemical elements on the surface. All the STM images were obtained at a sample bias of $-2.0 \mathrm{~V}$ and a set point tunneling current of $0.2 \mathrm{nA}$.

\section{Results and Discussion}

Nitridation of Ge(100) Surface

After ECR plasma nitridation at $500^{\circ} \mathrm{C}$ for $30 \mathrm{~min}$, the $\mathrm{Ge}(100)$ surface was covered by ordered and disordered Ge-N structures as shown in Figure 1(a). Only Ge and $\mathrm{N}$ peaks were detected in AES spectra, confirming the surface structures were formed purely due to nitrogen (data not shown). Figure 1(b) shows the STS results obtained from a clean $n$ type $\mathrm{Ge}(100)$ surface (dotted line) and a Ge surface nitrided at $500^{\circ} \mathrm{C}$ (straight line). On a clean $n$-type $\mathrm{Ge}(100)$ surface, the Fermi level $\left(\mathrm{E}_{\mathrm{F}}\right)$ appeared near the conduction band (CB) edge. However, after plasma nitridation, the Fermi level of a $n$-type Ge surface was pinned near the valence band (VB) edge. To investigate the relation between bonding and electronic structure of the ordered nitride, the DFT calculations were performed on a model structure with two subsurface $\mathrm{N}$ atoms tri-coordinated underneath the surface $\mathrm{Ge}$ dimer (Figure 2, upper left). After full relaxation, the topmost Ge dimers are slightly pushed up and tilted, consistent with the STM data (Figure 1(a)). The adsorption reaction is exothermic with respect to an atomic $\mathrm{N}(\Delta \mathrm{H}=-3.77 \mathrm{eV} / \mathrm{N})$, consistent with the thermal stability of the ordered nitride structure at $500^{\circ} \mathrm{C}$. However, the adsorption is endothermic with respect to molecular $\mathrm{N}_{2}(\Delta \mathrm{H}=1.45 \mathrm{eV} / \mathrm{N})$, consistent with the relatively low coverage of the ordered nitride structure even after a long exposure to atomic $\mathrm{N}$.

DFT calculations of density of states showed that plasma nitridation increases the states near the Fermi energy, consistent with the Fermi level pinning on the nitrided Ge 
surface (Figure 2, right). However, terminating all the dangling bonds on the nitride structure with $\mathrm{H}$ atoms is found to remove the tilt of Ge dimers (Figure 2, lower left) and reduced the bandgap states near the Fermi energy, possibly unpinning the Fermi level of the surface (Figure 2, right). This implies both dangling bonds and the bond strain due to the subsurface $\mathrm{N}$ atoms contribute the increase of the band gap states. Complementary experimental data were not available for the H-passivation due to the low nitridation rate and the residual plasma defects.

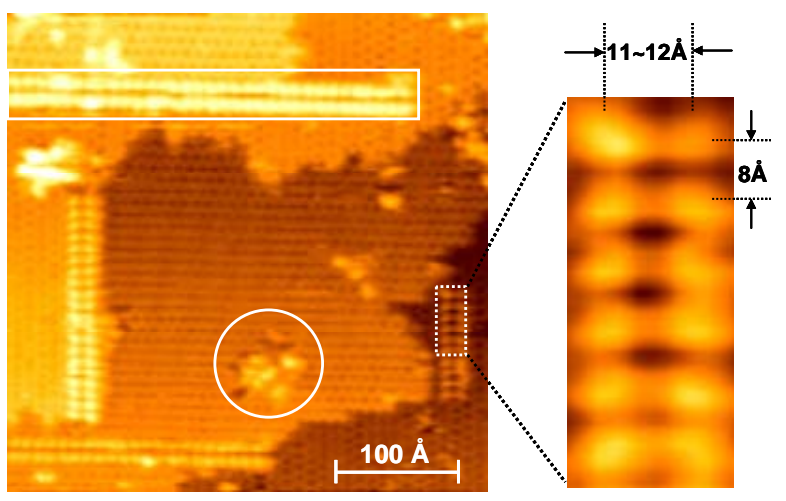

(a)

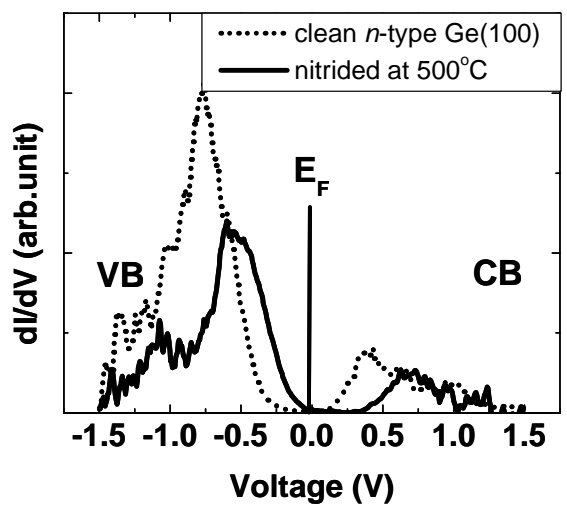

(b)

Figure 1. STM and STS of Plasma Nitrided Ge(100). (a) Filled state STM image of a $\mathrm{Ge}(100)$ surface nitrided at $500^{\circ} \mathrm{C}$. Ge-N ordered (rectangle) and disordered (circle) structures are shown. The dotted box is expanded for geometric analysis. (b) STS results on a clean Ge(100) (dotted) and a nitrided Ge surface (straight). Note that the Fermi level of $n$-type Ge is pinned near the valence band (VB) edge after plasma nitridation.
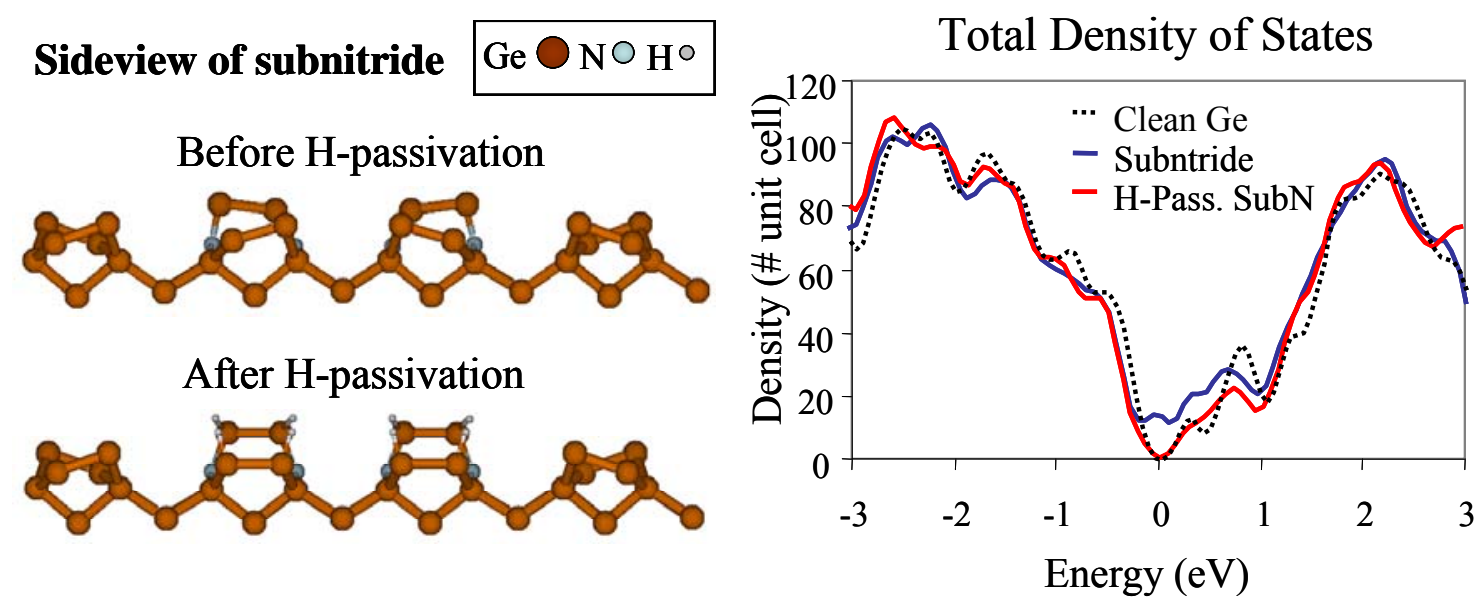

Figure 2. DFT Models of Nitrided Ge(100). (upper left) DFT model of subnitride with backbond insertion $\mathrm{N}$ sites. Each Ge surface atom has two half filled dangling bonds; (lower left) DFT model of H-passivated subnitride; (right) DFT calculations of the density of states shows the subnitride produces density near the Fermi energy, but hydrogen passivation removes the density around the Fermi energy unpinning the Fermi level of Ge surface. 


\section{$\underline{\text { Oxidation of } \mathrm{Ge}(100) \text { using } \mathrm{H}_{2}} \underline{\mathrm{O}}$}

Figure 3(a) shows the STM image of a $\mathrm{Ge}(100)$ surface dosed with $1.5 \mathrm{~L}$ of $\mathrm{H}_{2} \mathrm{O}$ at room temperature. The Ge surface is covered by approximately 0.1 monolayers (ML) of dark sites, which are due to the $-\mathrm{OH}$ and $-\mathrm{H}$ termination of Ge dangling bonds and consistent with the dissociative chemisorption of $\mathrm{H}_{2} \mathrm{O}$ on a $\mathrm{Ge}(100)$ surface (15). In the case of the $\mathrm{O}_{2}$-dosed $\mathrm{Ge}(100)$ surface, an equal amount of dark (O displacement) and bright (Ge at-atom) sites were produced due to the strong reactivity of each $\mathrm{O}$ atom to displace a Ge surface atom (14). In contrast, $\mathrm{H}_{2} \mathrm{O}$ dosing produces very few $\mathrm{Ge}$ ad-atoms, which makes $\mathrm{H}_{2} \mathrm{O}$ as a promising oxidant for a monolayer passivation of $\mathrm{Ge}$. However, there are also Ge dimer vacancies (DV) observed on the $\mathrm{H}_{2} \mathrm{O}$ dosed surface (Figure 3(a), diamond), which are distinguished from the $\mathrm{H}_{2} \mathrm{O}$ adsorbate sites by different depths ( 0.9 $\AA$ for $\mathrm{H}_{2} \mathrm{O}$ sites, $1.2 \AA$ for DV). These dimer vacancies are possibly due to $\mathrm{H}_{2} \mathrm{O}$ etching resulting in the Fermi level pinning of the $n$-type Ge surface after $\mathrm{H}_{2} \mathrm{O}$ dosing (Figure 4(a)).

The dark $\mathrm{H}_{2} \mathrm{O}$ sites are significantly reduced when the surface is annealed to $300^{\circ} \mathrm{C}$ (Figure $3(\mathrm{~b})$ ). Instead, primarily bright sites are observed with some dark suboxide rows which are typically observed on the $\mathrm{O}_{2}$-dosed surface at the same temperature (14). On the $\mathrm{Ge}(100)$ surface, $\mathrm{H}_{2}$ desorption occurs around $300^{\circ} \mathrm{C}$ (16). Therefore, it is assumed that the surface structures remaining at $300^{\circ} \mathrm{C}$ are mostly due to oxygen. The suboxide species at $300^{\circ} \mathrm{C}$ can cause the Fermi level pinning (Figure 4(b)), but $\mathrm{E}_{\mathrm{F}}$ moves slightly towards midgap, implying there might be other mechanisms involved in the Fermi level pinning at this temperature.

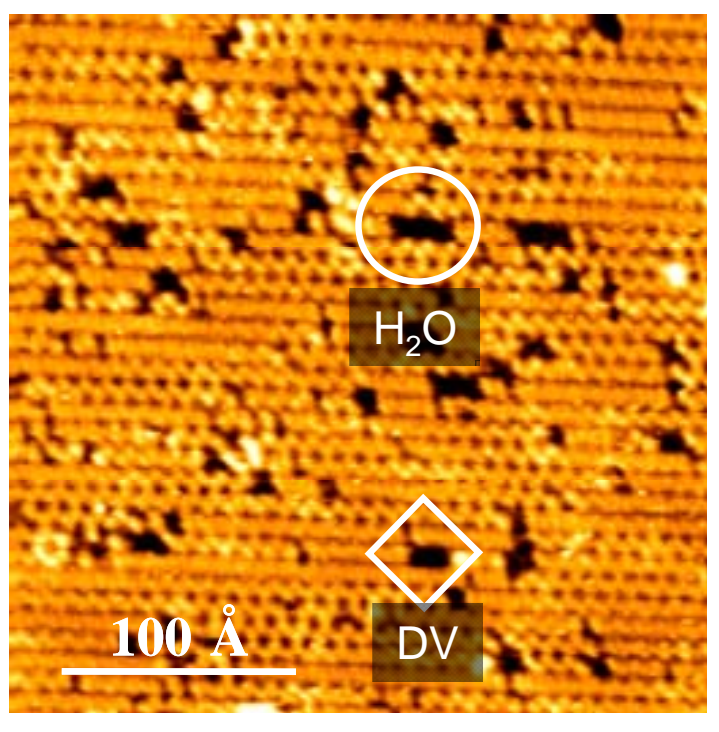

(a)

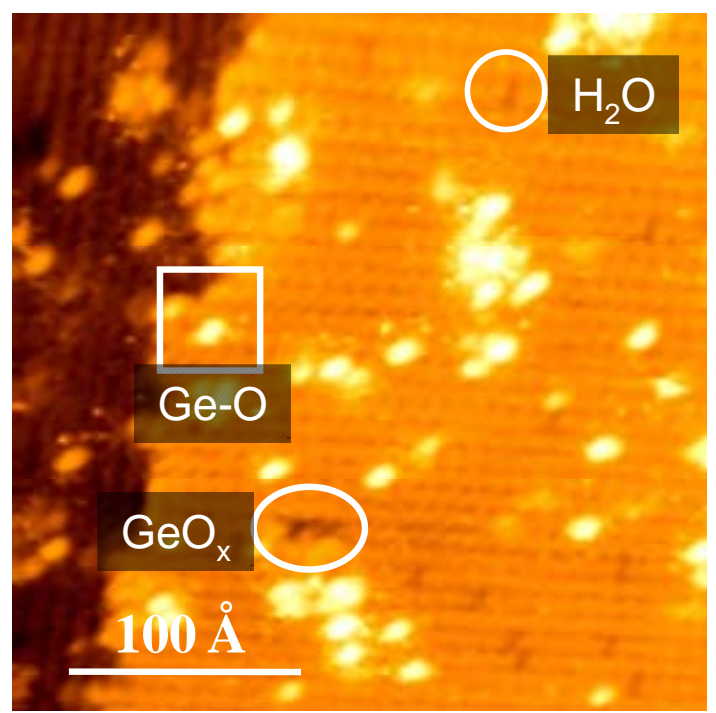

(b)

Figure 3. STM of $\mathrm{H}_{2} \mathrm{O} / \mathrm{Ge}(100)$ before and after post deposition annealing. (a) The $\mathrm{Ge}(100)$ surface dosed with $1.5 \mathrm{~L}$ of $\mathrm{H}_{2} \mathrm{O}$ at room temperature. $\mathrm{H}_{2} \mathrm{O}$ chemisorption sites (circle) and dimer vacancies (diamond) can be distinguished by different depths ( $0.9 \AA$ for $\mathrm{H}_{2} \mathrm{O}$ sites, $1.2 \AA$ for DV). (b) The $\mathrm{H}_{2} \mathrm{O}$ dosed $\mathrm{Ge}(100)$ surface after annealing at $300^{\circ} \mathrm{C}$. Due to the $\mathrm{H}_{2}$ desorption at this temperature, $\mathrm{H}_{2} \mathrm{O}$ sites (circle) are significantly reduced and bright Ge-O sites (square) are formed. Dark suboxide rows are also observed (oval). 


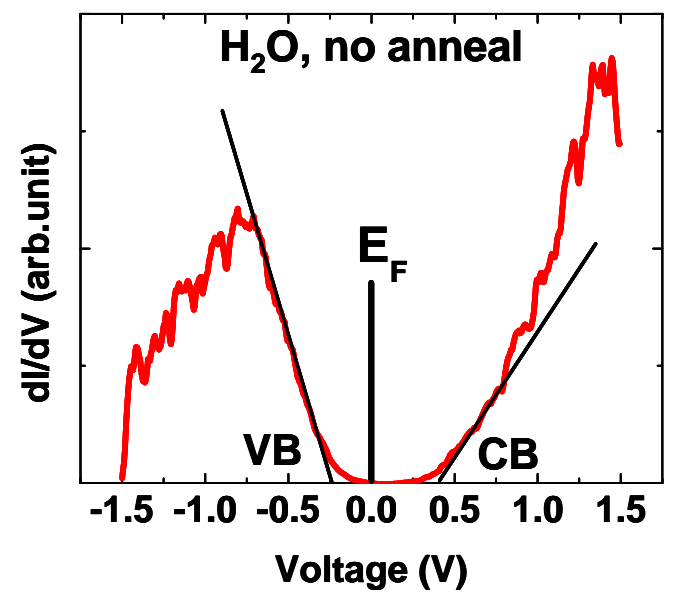

(a)

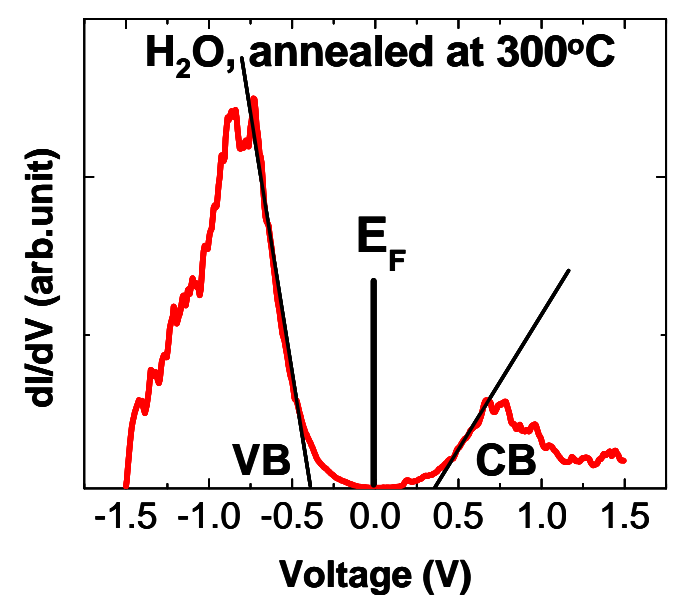

(b)

Figure 4. STS of $\mathrm{H}_{2} \mathrm{O} / \mathrm{Ge}(100)$ before and after post deposition annealing. (a) STS of $\mathrm{H}_{2} \mathrm{O}$ dosed $\mathrm{Ge}(100)$ at room temperature. The Fermi level of $n$-type Ge surface is pinned near the valence band edge. (b) STS of $\mathrm{H}_{2} \mathrm{O}$ dosed $\mathrm{Ge}(100)$ annealed at $300^{\circ} \mathrm{C}$. The Fermi level of $n$-type Ge surface is pinned near the midgap.

\section{$\underline{\text { Oxidation of } \mathrm{Ge}(100) \text { using E-beam evaporation of } \mathrm{GeO}_{2}}$}

E-beam evaporation of $\mathrm{GeO}_{2}$ at room temperature formed semi-ordered structures along the substrate Ge dimer rows and Ge ad-atoms on the Ge(100) surface (Figure 5(a)). It is known that $\mathrm{GeO}_{2}$ decomposes during e-beam evaporation, producing a substoichiometric film (17). Hence, the semi-ordered structures on the $\mathrm{GeO}_{2}$ deposited surface are likely Ge suboxides. It is also known that the Ge suboxide films undergo phase separation into $\mathrm{Ge}$ and $\mathrm{GeO}_{2}$ at elevated temperatures on a $\mathrm{Si}$ substrate (18). However, in the presence of excess $\mathrm{Ge}, \mathrm{GeO}_{2}$ transforms into $\mathrm{GeO}$ by the following reaction (19).

$$
\mathrm{Ge}+\mathrm{GeO}_{2} \rightarrow 2 \mathrm{GeO}
$$

Therefore, there would be only Ge or Ge suboxides remaining when the $\mathrm{GeO}_{2}$ deposited $\mathrm{Ge}(100)$ surface is annealed at $325^{\circ} \mathrm{C}$, consistent with the STM observation of Ge regrowth islands and suboxide rows (Figure 5(b)). The STS of $\mathrm{GeO}_{2}$ deposited $\mathrm{Ge}(100)$ surface indicate the Fermi level of the $n$-type sample surface is pinned near the valence band edge on both unannealed and annealed cases, probably due to the suboxide species. 


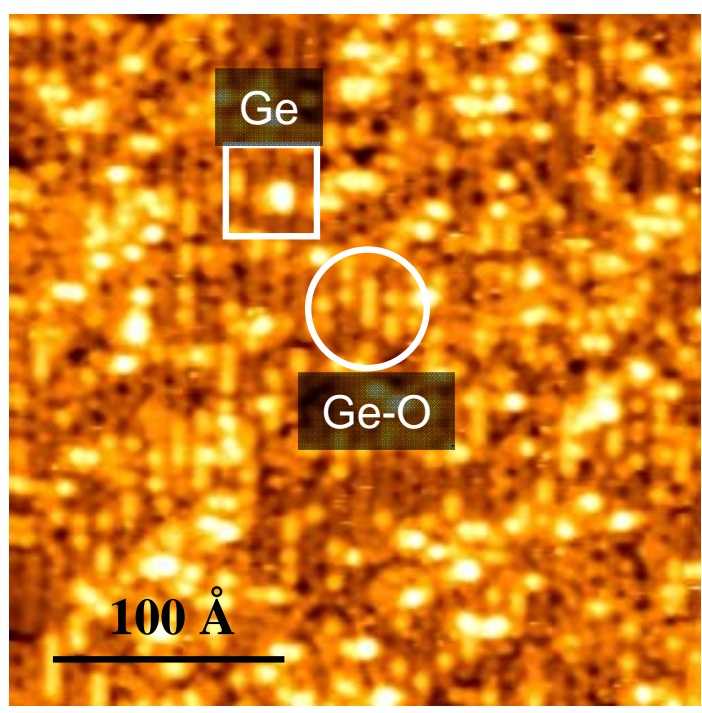

(a)

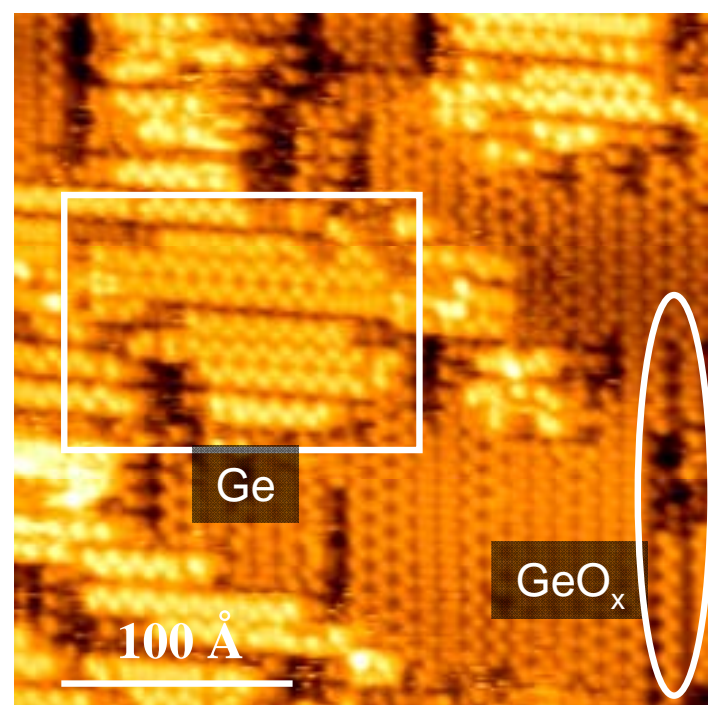

(b)

Figure 5. STM of ebeam $\mathrm{GeO}_{2}$ on $\mathrm{Ge}(100)$ before and after post deposition annealing. (a) $\mathrm{Ge}(100)$ surface deposited with $\mathrm{GeO}_{2}$ at room temperature. Semi-ordered Ge-O structures (circle) and Ge ad-atoms (square) are observed. (b) Ge(100) surface deposited with $\mathrm{GeO}_{2}$ after annealing at $325^{\circ} \mathrm{C}$. Ge regrowth island (rectangle) and suboxide rows (oval) are shown.

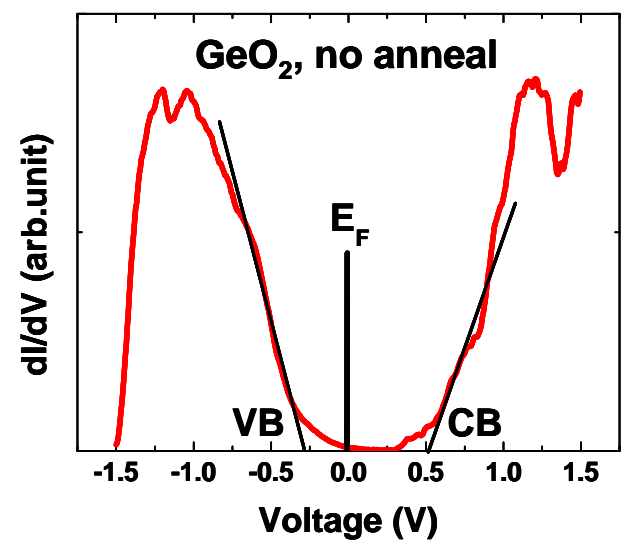

(a)

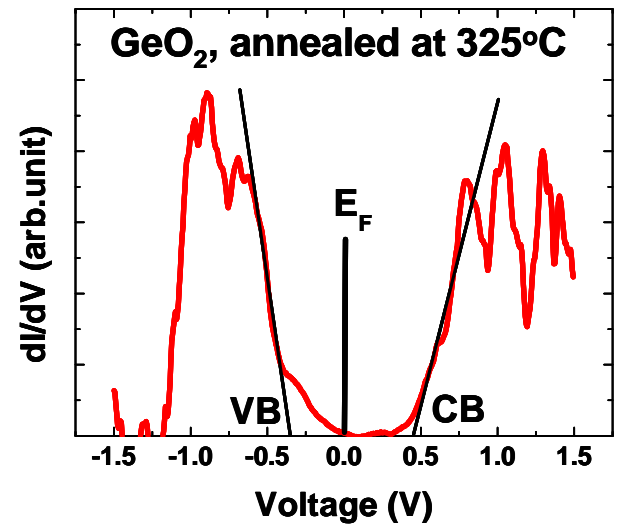

(b)

Figure 6. STS of e-beam $\mathrm{GeO}_{2}$ on $\mathrm{Ge}(100)$ before and after post deposition annealing. (a) STS of $\mathrm{GeO}_{2}$ deposited $\mathrm{Ge}(100)$ at room temperature. The Fermi level of $n$-type $\mathrm{Ge}$ surface is pinned near the valence band edge. (b) STS of $\mathrm{GeO}_{2}$ deposited on $\mathrm{Ge}(100)$ after annealing at $325^{\circ} \mathrm{C}$. The Fermi level of $n$-type Ge surface is pinned near the valence band edge.

\section{Conclusions}

The atomic and electronic structures of $\mathrm{Ge}(100)$ surface after nitridation and oxidation were investigated for the monolayer passivation of a $\mathrm{Ge}$ surface via $\mathrm{Ge}-\mathrm{N}$ and $\mathrm{Ge}-\mathrm{O}$ surface species. ECR plasma nitridation at $500^{\circ} \mathrm{C}$ produced an ordered $\mathrm{Ge}-\mathrm{N}$ structure on 
$\mathrm{Ge}(100)$, consistent with the thermal stability of the nitride passivation. However, the increase of dangling bonds and the bond strain due to the subsurface $\mathrm{N}$ atoms generated bandgap states resulting in Fermi level pinning of the Ge surface. DFT calculations showed that hydrogen passivation of the ordered subnitride structure can restore the Fermi level of the surface by eliminating the bandgap states from the dangling bonds and from strain. $\mathrm{H}_{2} \mathrm{O}$ dosing at room temperature terminated the dangling bonds on a $\mathrm{Ge}(100)$ surface with $-\mathrm{OH}$ and $-\mathrm{H}$ without displacing surface $\mathrm{Ge}$ atoms, while $\mathrm{GeO}_{2}$ deposition produced semi-ordered Ge-O structures with Ge ad-atoms. However, annealing above $300^{\circ} \mathrm{C}$ formed suboxide rows on both $\mathrm{H}_{2} \mathrm{O}$ and $\mathrm{GeO}_{2}$ dosed surfaces, causing the Fermi level pinning..

\section{Acknowledgments}

This work was supported by the MSD Focus Center Research Program (FCRP-MSD2051.001). In addition, S. R. Bishop was supported by a GLOBALFOUNDRIES sponsored GRC Graduate Fellowship.

\section{References}

1. B. De Jaeger, R. Bonzom, F. Leys, O. Richard, J. Van Steenbergen, G. Winderickx, E. Van Moorhem, G. Raskin, F. Letertre, T. Billon, M. Meuris, and M. Heyns, Microelec. Eng., 80, 26 (2005).

2. R. Xie, M. Yu, M.Y. Lai, L. Chan, C. Zhu, Appl. Phys. Lett., 92, 163505 (2008).

3. T. Maeda, S. Takagi, T. Ohnishi, M. Lippmaa, Mat. Sci. Semicon. Proc., 9, 706 (2006).

4. H. Kim, P.C. McIntyre, C.-O. Chui, K.C. Saraswat, M.-H. Cho, Appl. Phys. Lett., 85, 2902 (2004).

5. T. Maeda, T. Yasuda, M. Nishizawa, N. Miyata, Y. Morita, S. Takagi, J. Appl. Phys., 100, 014101 (2006).

6. Y. Oshima, Y. Sun, D. Kuzum, T. Sugawara, K.C. Saraswat, P. Pianetta, P.C. McIntyre, J. of Electrochem. Soc., 155, G304 (2008).

7. A. Delabie, F. Bellenger, M. Houssa, T. Conard, S. VanElshocht, M. Caymax, M. Heyns, M. Meuris, Appl. Phys. Lett., 91, 082904 (2007).

8. F. Bellenger, M. Houssa, A. Delabie, V. Afanasiev, T. Conard, M. Caymax, M. Meuris, K. DeMeyer, M.M. Heyns, J. of Electrochem. Soc., 155, G33 (2008).

9. D. Kuzum, T. Krishnamohan, A.J. Pethe, A.K. Okyay, Y. Oshima, Y. Sun, J.P. McVittie, P.A. Pianetta, P.C. McIntyre, K.C. Saraswat, IEEE Elec. Dev. Lett., 29, 328 (2008).

10. H. Matsubara, T. Sasada, M. Takenaka, S. Takagi, Appl. Phys. Lett., 93, 032104 (2008).

11. C.H. Lee, T. Tabata, T. Nishimura, K. Nagashio, K. Kita, A. Toriumi, ECS Trans., 19(1), 165 (2009).

12. T. Maeda, M. Nishizawa, Y. Morita, S. Takagi, Appl. Phys. Lett., 90, 072911 (2007).

13. S.J. Wang, J.W. Chai, J.S. Pan, A.C.H. Huan, Appl. Phys. Lett., 89, 022105 (2006).

14. T. J. Grassman, S. R. Bishop, and A. C. Kummel, Surf. Sci., 602, 2373 (2008). 
15. S.J. Jung, J.Y. Lee, S. Hong, and S. Kim, J. Phys. Chem. B, 109, 24445 (2005).

16. S. Shimokawa, A. Namiki, M. N.-Gamo, and T. Ando, J. Chem. Phys., 113, 6916 (2000).

17. Y. Batra, D. Kabiraj, D. Kanjilal, Solid State Commun., 143, 213 (2007).

18. M. Ardyanian, H. Rinnert, X. Devaux, and M. Vergnat, Appl. Phys. Lett., 89, 011902 (2006).

19. K. Prabhakaran, F. Maeda, Y. Watanabe, T. Ogino, Thin Solid Films, 369, 289 (2000). 